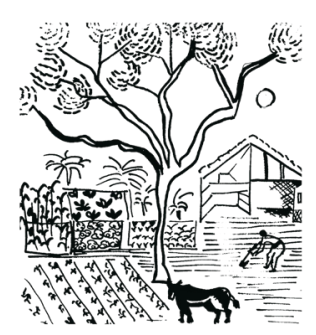

\title{
Mulheres camponesas e agroecologia em contexto de reforma agrária: experiências do acampamento Herdeiros da Terra
}

\author{
Clair Odete Schneider ${ }^{1}$ \\ Josiane Carine Wedig ${ }^{2}$ \\ Thiago de Oliveira Vargas ${ }^{3}$
}

ReSUmo: Este artigo aborda a relação de mulheres camponesas com a agroecologia em contexto de reforma agrária. A pesquisa foi desenvolvida através de observação participante e entrevistas semiestruturadas com quatorze mulheres que integram o Acampamento Herdeiros da Terra de $1^{\circ}$ de Maio, no município de Rio Bonito do Iguaçu, no Paraná. A análise está pautada nos temas da divisão sexual do trabalho e hierarquização das atividades que são realizadas no lote de cada família. Ao longo da pesquisa, observou-se que as mulheres participam de modo ativo em diversas atividades que ocorrem no acampamento, no entanto, ainda prevalecem inúmeros padrões de práticas patriarcais no seu cotidiano.

Palavras-chave: Mulheres camponesas. Agroecologia. Reforma Agrária.

\section{Peasant women And agroecology in the Context of agrarian reform: the HERDEIROS DA TERRA ENCAMPMENT EXPERIENCE}

Aвstract: This article addresses the relationship between peasant women and agroecology in the context of land reform. The research was developed through participant observation and semi-structured interviews with fourteen women who are part of the Herdeiros da Terra Camp of $1^{\circ}$ de Maio, in the municipality of Rio Bonito do Iguaçu, in Paraná. The analysis is based on the themes of the sexual division of labor and the hierarchy of activities that are carried out in the lot of each family. Throughout the research, it was observed that women actively participate in various activities that take place in the camp, however, numerous patterns of patriarchal practices still prevail in their daily lives.

KEYWORDS: Peasant women. Agroecology. Land reform.

\footnotetext{
${ }^{1}$ Graduada em Psicologia pela Universidade Comunitária da região de Chapecó (UNOCHAPECÓ), Pós- Graduada em Avaliação Psicológica e Diagnóstico pela Universidade do Oeste de Santa Catarina (UNOESC) e mestre em Desenvolvimento Regional pela Universidade Tecnológica Federal do Paraná (PPGDR/UTFPR). E-mail: clair-schneider@unochapeco.edu.br ${ }^{2}$ Doutora em Ciências Sociais pela Universidade Federal Rural do Rio de Janeiro (CPDA/UFRRJ), professora adjunta do Departamento de Ciências Humanas e do Programa de Pós-Graduação em Desenvolvimento Regional da Universidade Tecnológica Federal do Paraná (PPGDR/UTFPR). E-mail: josiwedig@gmail.com

${ }^{3}$ Doutor em Fitotecnia pela Universidade Federal de Viçosa (UFV). Professor permanente do Programa de Pós-Graduação em Agronomia da Universidade Tecnológica Federal do Paraná (PPGAG/UTFPR). E-mail: thiagovargas@utfpr.edu.br
} 


\section{INTRODUÇÃo}

Neste estudo serão discutidas questões relacionadas às mulheres camponesas, considerando o contexto de agroecologia e reforma agrária. Diversos estudos têm demonstrado como as mulheres camponesas foram invisibilizadas e alijadas de direitos, visto que não eram reconhecidas pelo Estado. Algumas autoras que contribuem para esta pesquisa através de suas análises e discussões sobre as desigualdades vivenciadas pelas mulheres são Paulilo, Siliprandi, Boni e Pacheco. Serão abordadas também as possibilidades de empoderamento vivenciadas pelas mulheres através dos movimentos sociais e da prática agroecológica no acampamento Herdeiros da terra de $1^{\circ}$ de maio. Durante muito tempo, as mulheres camponesas foram reconhecidas apenas como "do lar" e não como trabalhadoras e agricultoras, dificultando as possibilidades de acesso a direitos como aposentadoria e salário maternidade, além de não conseguirem linhas de crédito. No Brasil, apenas com a Constituição Federal de 1988, as mulheres passaram a obter alguns direitos, como igualdade, direitos sociais, políticos e trabalhistas, entre uma série de outras conquistas.

Ao longo deste estudo, observou-se que, de fato, por mais que existam muitas mulheres que já ocupam espaços públicos, cargos de liderança, ainda há um bom número delas que estão restritas ao espaço doméstico ou a seus arredores, mesmo que participem do Movimento dos Trabalhadores Rurais Sem Terra (MST), que possui inúmeras discussões sobre a temática de gênero. Refletir sobre essas questões é necessário para que se construam novas relações de gênero, respeitando, valorizando e visibilizando as atividades desenvolvidas pelas mulheres, no sentido de reconhecê-las enquanto agricultoras e trabalhadoras e não apenas, como domésticas, ajudantes ou dependentes de seus pais/maridos.

O estudo foi realizado no acampamento de reforma agrária Herdeiros da Terra de $1^{\circ}$ de maio, localizado nas cidades de Rio Bonito do Iguaçu e Nova Laranjeiras, no estado do Paraná, Brasil. Esse acampamento foi constituído no ano de 2014 e é formado por 2.500 famílias.

O acampamento está dividido em 22 grupos que foram organizados via sorteio ou por consenso das famílias. Cada grupo é formado por famílias que estão localizadas pela proximidade, que se organizam para as discussões referentes à produção, organização, militância e às ações no acampamento. Três desses grupos trabalham com a produção agroecológica, totalizando 45 famílias.

O acampamento Herdeiros da Terra de $1^{\circ}$ de maio é decorrente da ocupação da terra que estava sob o domínio da empresa madeireira Araupel, acusada de grilagem de terras. A nominação do acampamento possui um significado importante, pois está relacionada ao fato de que grande parte dos sem-terra que 
o constituiu são descendentes de famílias que ocuparam terras, em 1996, em latifúndios da Araupel, demonstrando que há uma segunda geração (de filhos e filhas) que também está ocupando novas terras para a continuidade da reprodução camponesa, dando seguimento à luta pela terra. Além disso, há a referência à data de $1^{\circ}$ de maio, que é o dia em que o acampamento começou a ser organizado (CEZIMBRA; PASTÓRIO; XAVIER, 2017). Atualmente, o acampamento possui 1103 famílias, com um número aproximado de quatro mil pessoas vivendo nessas terras.

No mês de agosto de 2018, ocorreu uma reorganização do acampamento que, até então, estava constituído enquanto uma área de trabalho e de vida coletiva. Nesse período, diante da demora do Instituto Nacional de Colonização e Reforma Agrária (Incra) em regularizar a área e fazer a divisão em lotes, as/os acampadas/ os deliberaram que dividiriam a área em lotes familiares. Como consequência disso, os moradores enfrentam uma nova realidade de organização e estruturação dos grupos e das atividades, que antes eram realizadas de modo conjunto e em áreas coletivas, e que, atualmente, são desenvolvidas por cada família em seu lote.

A pesquisa teve como público alvo as mulheres camponesas do acampamento Herdeiros da Terra de $1^{\circ}$ de maio com o objetivo de compreender as relações de gênero existentes nesse espaço e a sua conexão com a agroecologia. Foram pesquisados os três grupos que trabalham com agroecologia no acampamento, através de quatorze entrevistas semiestruturadas realizadas com as mulheres que deles participam. Buscou-se, desse modo, compreender a organização delas enquanto coletivo no MST e analisar como a prática agroecológica permite a elas novas oportunidades e reconhecimento enquanto trabalhadoras rurais.

A aproximação com as lideranças dos grupos e do acampamento ocorreu a partir do segundo semestre de 2018, quando se apresentou para as interlocutoras os objetivos da pesquisa, cujo trabalho de campo teve continuidade durante todo o ano de 2019.

O texto está organizado em quatro sessões, inicia-se abordando as situações cotidianas vivenciadas pelas mulheres no sistema patriarcal da nossa sociedade e se segue discutindo a invisibilidade e os enfrentamentos das mulheres camponesas, as lutas pela reforma agrária e a agroecologia como um importante instrumento para o empoderamento dessas mulheres.

\section{O PATRIARCADO E AS DESIGUALDADES VIVENCIADAS PELAS MULHERES}

Para compreender as desigualdades vivenciadas pelas mulheres camponesas, é necessário abordar, brevemente, como se estabelecem as desigualdades mais gerais sobre essas na sociedade moderna. Há diversas formas de opressão enfrentadas 
por elas desde a infância, que se naturalizam em decorrência dos modos de organização social e que estruturam as relações da sociedade, tendo como pilar central o sistema patriarcal.

O enfrentamento ao patriarcado demanda reflexões sobre os modos como se constroem e se estabelecem as relações tanto em espaços privados, nos quais o homem é descrito como o "chefe" de família, quanto nos contextos públicos, em que ele ocupa o poder central no Estado e nas formas hegemônicas de religião, medicina e de justiça. O patriarcado afeta as mulheres no mercado de trabalho, através da divisão sexual desse e também na maneira como elas são educadas para a vida social, pois desde crianças experienciam atividades específicas ao seu sexo, diferente do que acontece com os homens. Tais formas de organização e enquadramento resultam nas possibilidades e experiências que cada qual irá estabelecer ao longo da vida, desde o âmbito profissional até as relações sociais, da infância à vida adulta (SAFFIOTI, 2015; BEAUVOIR, 1967)

$\mathrm{Na}$ divisão sexual do trabalho, as mulheres são responsáveis pelas tarefas domésticas e pelo cuidado com as/os filhas/os. Para Beauvoir (1967), esses moldes corporificam-se desde os brinquedos disponibilizados para as crianças até os espaços que elas frequentam. No caso das mulheres interlocutoras desta pesquisa, a divisão sexual do trabalho é marcante tanto no espaço doméstico como no público do acampamento.

Dessa maneira, fica nítido que, por mais que as mulheres tenham dito que a divisão do trabalho ocorre de modo igualitário entre o casal, ainda permanece a concepção de que o trabalho que o homem desempenha é mais "pesado" e/ou mais "difícil" do que o trabalho desempenhado pelas mulheres. Essa divisão entre trabalho "leve" e "pesado" é explicada por Paulilo (1987) a partir de observações que realizou em diferentes áreas rurais. De acordo com a autora, nesse contexto,

[...] a distinção entre trabalho "leve" e "pesado" se faz mais clara. Entre os trabalhadores volantes, é "pesado", masculino, principalmente roçar e cavar a terra. Roçar significa derrubar o mato grosso, inclusive árvores, a machado e foice. Cavar é preparar a terra, sem ajuda do arado, para o plantio da cana. Trabalho "leve", feminino, é plantar, arrancar o mato miúdo, e adubar. Para isso, as mulheres ganham a metade, ou menos, da diária de um homem, embora trabalhem o mesmo número de horas (PAULILO, 1987, s. p.).

As desigualdades existentes entre homens e mulheres foram mencionadas pelas acampadas de forma intensa, porém, na maioria dos casos, elas descreveram a existência dessas dificuldades, de modo mais geral, na sociedade, e não apenas 
como parte das suas vivências cotidianas. Elenir aponta que ainda "[...] é a mulher quem cuida das tarefas da casa, tira o leite das vacas, cuida dos animais e ainda ajuda na roça e o homem, chega da roça, toma banho e vai descansar. Isso acontece muito" (Entrevista realizada em maio, 2019). Desse modo, as mulheres têm compreensão sobre as desigualdades que vivenciam; no entanto, é muito mais difícil quebrar paradigmas sociais, principalmente com relação à educação sexual e social diferenciada para homens e mulheres. Jaqueline entende que ainda há muito para se avançar para que as mulheres consigam alcançar um patamar de igualdade, de reconhecimento e de direitos. Para ela "existem desigualdades, a mulher acaba tendo uma jornada dupla, trabalha 'fora' e 'dentro' de casa e o homem apenas fora, assim ela acaba se sobrecarregando" (Entrevista realizada em agosto, 2019).

Para Juliana, as mulheres foram moldadas para realizar essas tarefas como deveres do seu dia a dia. Desse modo, mesmo que as tarefas sejam divididas, de alguma maneira, as mulheres acabam por ter mais responsabilidades do que os homens. Ela descreve que na sua casa,

[...] a gente sempre dividiu. Mesmo assim, eu não conheço nenhuma mulher que trabalhe menos que o homem dento de casa, pode até dividir a maioria das tarefas, mas parece que tem coisas que a nossa educação nos faz enxergar e a dos homens não, faz com que eles não enxerguem (Entrevista realizada em maio, 2019).

Nesses papéis sociais naturalizados, centram-se diversas compreensões referentes às situações de violência e as opressões vivenciadas pelas mulheres enquanto objetos da sociedade e do patriarcado. Nessa organização social, nem sempre as mulheres questionam sua inferiorização. Para Saffioti (2015), esse modo de organização social é muito mais do que apenas uma ordem sexista de divisão sexual do trabalho, mas, sim, uma estrutura de poder que resulta em relações extremamente desiguais para as mulheres. Para isso,

As mulheres são "amputadas", sobretudo no desenvolvimento e uso da razão e no exercício do poder. Elas são socializadas para desenvolver comportamentos dóceis, cordatos e apaziguadores. Os homens, ao contrário, são estimulados a desenvolver condutas agressivas, perigosas, que revelem força e coragem (SAFFIOTI, 2015, p. 37).

Essa forma de educação diferenciadareflete nas relações de poder que estruturam a sociedade. Outra classificação social instituída na sociedade patriarcal são os

\footnotetext{
${ }^{1} \mathrm{O}$ trabalho 'fora', descrito pelas mulheres é o trabalho realizado na propriedade rural para a produção que será comercializada
} e pode se referir também ao trabalho assalariado na cidade ou em outra propriedade rural. 
"acessos" e as liberdades destinados às mulheres e aos homens; um exemplo muito significativo é a vivência da sexualidade, aos homens é dada como necessária e importante, enquanto para as mulheres é considerada como pecaminosa e errada.

Desse modo, na sociedade patriarcal não são abordadas problemáticas que envolvam a coletividade, ao contrário, utiliza-se do desequilíbrio, do desenvolvimento desigual entre homens e mulheres para manter o controle e o poder. Ao abordar a situação das mulheres nos espaços públicos e privados, observa-se que essas valorizam muito as liberdades já conquistadas, porém, em muitas situações, deixam de questionar as desigualdades atuais existentes entre homens e mulheres, as quais são decorrentes da ordem patriarcal vigente (SAFFIOTI, 2015).

Para entender as situações patriarcais vivenciadas pelas mulheres na sociedade atual, é preciso compreender que o patriarcado passou por diversas transformações. $\mathrm{Na}$ Roma antiga, o patriarca detinha o poder sobre a vida e a morte das mulheres e das/os filhas/os; hoje, esse poder não existe, no entanto, diariamente somos bombardeadas/os por notícias nas quais os homens continuam matando suas esposas e companheiras, demostrando a permanência da ideia de poder patriarcal sobre a vida e os corpos das mulheres (SAFFIOTI, 2015).

Além do poder sobre os corpos, a vida e a morte das mulheres, a sociedade patriarcal considera-se apta a julgar a sexualidade delas e de suas escolhas. Para Saffioti (2015), um dos elementos centrais do patriarcado tem como objetivo o controle da sexualidade feminina, a fim de assegurar a fidelidade da esposa. A autora entende que as mulheres brasileiras possuem inúmeras razões para se opor ao machismo existente em todas as instituições sociais, sabendo que o patriarcado não existe apenas no contexto familiar, mas atravessa a sociedade como um todo.

Todos esses espaços apresentam relações de poder marcadas pelo sexo de quem realiza as atividades ou possui maior ou menor poder sobre as/os demais sujeitas/ os. A posição das mulheres, nesse contexto patriarcal, é marcada por relações de poder e machismo, inferioridade, invisibilidade e falta de reconhecimento das capacidades e atividades desempenhadas por elas.

Para compreender o conceito de patriarcado, deve-se levar em conta que existe um processo de dominação fortemente presente nas relações entre homens e mulheres. O contrato social relaciona-se à liberdade, o contrato sexual relaciona-se à submissão e o contrato original cria a liberdade e a dominação, sendo a liberdade reservada ao homem e a submissão à mulher. Nesse sentido, a liberdade civil não é universal, é um direito masculino e associado diretamente ao poder patriarcal (PATEMAN, 1993 apud SAFFIOTI, 2015).

A sociedade patriarcal não é uma característica apenas do espaço familiar, 
nas relações matrimoniais e familiares, mas também do contexto público, que é observado no Estado. Nessa perspectiva, a liberdade civil depende do direito e das regras de uma sociedade patriarcal, referentes a um contrato entre os homens, no qual as mulheres são objetos. O poder político também é fortemente expresso através do patriarcado (SAFFIOTI, 2015).

Para Saffioti (2015), muitas análises sobre o patriarcado voltam-se às relações e aos vínculos familiares, as quais, no entanto, são decorrentes de padrões universais e que estruturam a sociedade moderna. Para a autora, a dominação do patriarcado, está pautada nos seguintes princípios:

1- Não se trata de uma relação privada, mas civil; -2 Dá direitos sexuais aos homens sobre as mulheres, praticamente sem restrição [...]; 3-Configura um tipo hierárquico de relação que invade todos os espaços da sociedade; 4- Tem uma base material; 5- Corporifica-se; 6- Representa uma estrutura de poder; 7-Baseada tanto na ideologia quanto na violência (SAFFIOTI, 2015, p. 60).

Através das lutas dos movimentos feministas muito se avançou em termos de conquistas dos direitos das mulheres; no entanto, as disparidades referentes às inferioridades relacionadas à classificação sexual dos sujeitos, ainda permanecem em diversos âmbitos. Ao tratar do mercado de trabalho, a divisão sexual desse ocorre com relação ao critério de classificação sexual dos sujeitos, no qual ocorre a desvalorização das atividades desempenhadas pelas mulheres quando comparadas as dos homens.

A concepção de que o trabalho doméstico é característico do sexo feminino é possível de ser observada quando, em muitos casos, as mulheres compreendem que maridos ou filhos não fariam tão bem os afazeres domésticos quanto elas. Não por uma questão de ambição, mas por crenças que foram impostas a elas referentes ao seu dever e comprometimento com tais tarefas. Essas atividades, comumente desempenhadas por mulheres, apenas são consideradas difíceis ou cansativas se associadas a outras que forem desenvolvidas fora do ambiente do lar; no entanto, caso seja essa a principal atividade que a mulher desempenha, é considerada como pouca e simples de se realizar (BEAUVOIR, 1967). Através da luta feminista, possibilitou-se a construção de uma identidade coletiva como uma forma de se organizar, enfrentando as situações de injustiça com relação às mulheres. Na seção seguinte, será discutida a invisibilidade vivenciada pelas mulheres camponesas.

\section{A INVISIBILIDADE DAS MULHERES CAMPONESAS}

Nos mais diferentes espaços da sociedade é possível refletir sobre as diversas 
formas de invisibilização, opressão e violência relacionadas às mulheres. No contexto rural, com a industrialização da agricultura, as tarefas realizadas pelas mulheres passam a ser voltadas para as práticas de cuidado e de preparação de alimentos para a família e essas são consideradas atividades complementares, menos importantes do que as das lavouras comerciais - que passam a estar centradas nas monoculturas, consideradas as atividades principais e sob a responsabilidade dos homens (SILIPRANDI, 2011).

Desse modo, no espaço rural, o trabalho das mulheres passou a ser o do cuidado com a casa e de seus arredores, a responsabilidade pelas atividades domésticas, a incumbência com as crianças, os idosos e os doentes, a preparação da comida, o zelo pela saúde dos familiares, o manejo da horta e dos pequenos animais, focadas na produção para o autoconsumo. Em oposição, está o trabalho realizado pelos homens, atrelado à produção destinada à comercialização. Essa classificação da divisão do trabalho ocorre mesmo em contextos em que tanto homens quanto mulheres produzem alimentos para a venda ou para o consumo da família (PAULILO, 2004).

Siliprandi (2011) chama atenção para a necessidade de levar em consideração esses nexos existentes entre o trabalho que produz valor de troca para o mercado e as atividades consideradas como de reprodução (trabalho doméstico, de cuidados, de autoconsumo), pois ambos são essenciais para a sobrevivência das famílias rurais. Isso, contudo, não quer dizer que as relações de poder imbricadas nessas atividades não devam ser questionadas ou revistas, pois essa classificação, que é simbólica e hierárquica, tem significado a atribuição exclusiva às mulheres do trabalho doméstico/reprodutivo, o que, na grande maioria dos casos, acarreta uma dupla jornada de trabalho para elas. É a partir da naturalização da condição biológica das mulheres, relacionada à sua capacidade de gerar filhos, que se opera a normatização dos papéis atribuídos a homens e mulheres, produzindo-se desigualdades que, em muitos casos, têm significado a subordinação dessas, seja na dupla jornada de trabalho que elas enfrentam, seja na invisibilidade de seu papel para a agricultura familiar/camponesa (BRUMER; PAULILO, 2004).

De acordo com Siliprandi (2011), as primeiras lutas das agricultoras no País foram pelo reconhecimento da sua profissão, pelo acesso à terra, para que seus nomes estivessem no bloco de produção rural e fossem reconhecidas em seus documentos como agricultoras, para a possibilidade do exercício de seus direitos sociais, previdenciários e sindicais e a obtenção de melhores atendimentos nos sistemas de saúde e educação.

Outro aspecto que chama a atenção em relação aos direitos das mulheres agricultoras é que as "políticas de desenvolvimento rural ainda são decididas e implantadas sem a participação ativa das mulheres e sem levar em consideração 
os seus pontos de vista [...]" (SILIPRANDI, 2011, p. 177). Essa exclusão e o não reconhecimento delas refletem-se na perda de benefícios e direitos e na sua invisibilização enquanto trabalhadoras rurais (SILIPRANDI, 2011).

Nesse contexto sócio-histórico, os homens foram denominados e reconhecidos como os "chefes de família" que passaram a ser responsáveis pelas lavouras de monoculturas, que produziam para o mercado, enquanto as mulheres passam a ser vistas, como dependentes ou ajudantes, responsáveis pelo trato da casa e seus arredores, além do cuidado com os filhos (PAULILO, 2016). O papel das mulheres no meio rural é considerado, em muitas situações, como um fator de complementação ao trabalho do homem, sendo um auxílio às atividades que promovem e geram ganho econômico na propriedade rural.

Historicamente as mulheres estiveram presentes nas atividades do meio rural, tendo uma participação essencial para seu círculo familiar e social, realizando todas as atividades da propriedade rural e como responsáveis pelas lidas domésticas. Porém, nem sempre elas foram reconhecidas como trabalhadoras rurais, eram antes nominadas como "do lar", pois seu trabalho era classificado como "trabalho leve” e fácil e o realizado pelos homens era considerado difícil e "pesado”. Essa divisão entre trabalho "leve" e "pesado" é explicada por Paulilo (1987) a partir de observações que ela realizou em diferentes áreas rurais. A autora observou que o trabalho realizado pelas mulheres em diferentes regiões do Brasil era concebido como leve, em oposição ao trabalho dos homens, classificado como pesado. No entanto, a autora indica que isso não se devia ao esforço despendido, mas ao sexo de quem o executava.

As questões de gênero estão presentes em diferentes contextos da sociedade, porém, no meio rural, elas contém algumas especificidades decorrentes dos papéis sociais atribuídos às mulheres, como "ajudantes" ou "dependentes" de seus companheiros, pelas atividades que cada qual hierarquicamente realiza na propriedade rural, pela renda indivisível, pelo não reconhecimento e pela invisibilidade enquanto trabalhadoras rurais (CHAYANOV, 1974; DEERE; LEON, 2002; PAULILO, 2016). As atividades demandadas e as formas de organização, em muitos casos, reprimem e excluem a participação das mulheres. Essa herança hierárquica de exclusão atribui às mulheres funções que estariam "naturalmente" ligadas à maternidade e, consequentemente, ao cuidado das/os filhas/os e do lar, enquanto os homens assumiriam funções no contexto fora do lar (MEDEIROS, 1989).

A partir da organização coletiva das mulheres, essas criaram reivindicações com relação aos direitos à terra, ao voto, à saúde, à educação etc. e com o processo de mobilização, passa-se a discutir não apenas a posse da terra, mas outros inúmeros 
fatores ligados às relações de poder estabelecidas, como, por exemplo, os casos de violência. As percepções sobre os papéis sociais atribuídos às mulheres não se limitam apenas a compreender sua participação na luta pela terra, mas também entender como ocorre sua atuação em todas as atividades que lhe são demandadas, tornando-se "[...] central analisar o processo pelo qual se dá a constituição desses novos lugares das mulheres. A questão subjacente é a de como se constituem possibilidades de desnaturalização da dominação" (MEDEIROS, 1989, p. 11).

Como consequência das reivindicações dos movimentos sociais de mulheres camponesas na busca pela ampliação dos direitos e da conquista de melhores condições de vida, é possível verificar que as desigualdades entre homens e mulheres ainda existem no contexto rural e são reconhecidas, em muitos casos, como naturais, sob a estruturação das relações de poder existentes na sociedade. Mesmo com muitas lutas, as mulheres ainda permanecem em situação de não reconhecimento, por parte do Estado, pelas atividades desempenhadas enquanto agricultoras cam ponesas e assentadas pela reforma agrária (BUTTO; HORA, 2008).

Comumente, as políticas públicas voltadas para o meio rural, em sua maioria, direcionam-se à família rural, considerando o todo como homogêneo e imparcial, mas quem assume o papel central é o homem. Após lutas e reivindicações, no entanto, passou-se a repensar sobre as estruturas familiares, reconhecendo a diversidade ea pluralidade do campesinato e da agricultura (BUTTO; HORA, 2008).

As mulheres afirmam que muito se avançou na relação entre homens e mulheres, já que hoje as mulheres possuem muito mais oportunidades e espaço para se posicionar na sociedade. Em seguida, será abordada a participação e importância das mulheres nos contextos de reforma agrária.

É possívelverificaras dificuldades das mulheresemobteremoutros direitos, como o econômico, a assistência técnica, o crédito e o mercado para a comercialização dos produtos excedentes da produção familiar. Essa concepção é derivada de uma organização da agricultura camponesa, a qual se centra no poder patriarcal. $O$ trabalho nas comunidades rurais organiza-se a partir da divisão sexual do trabalho, na qual as mulheres são responsáveis pelo trabalho reprodutivo e pelos cuidados domésticos e os homens pelo trabalho gerador de rendas monetárias, reconhecido como produtivo (BUTTO; HORA, 2008, p. 22-23). Na lógica patriarcal os hábitos culturais e os costumes normatizam e centralizam o poder na figura masculina. Nessa percepção, as mulheres são vistas como um patrimônio masculino, ou seja, pertencentes aos homens, pois são vistas como dependentes de seus pais ou maridos.

Mesmo com a criação de estratégias para a valorização e o reconhecimento das mulheres que vivem e trabalham no meio rural, ainda se percebe a existência de muitas limitações e empecilhos que impedem o desenvolvimento da sua autonomia 
econômica, o que também pode ser observado em contextos de reforma agrária, no qual as mulheres ainda sofrem com a falta de reconhecimento, valorização e visibilidade das atividades desempenhadas por elas (BUTTO; HORA, 2008).

Nesse sentido, torna-se necessário concretizar ações que fortaleçam a estruturação, organização, coordenação e reconhecimento das mulheres rurais e as atividades desenvolvidas por elas. Os desafios ainda são muitos, mas também já existem muitos direitos conquistados que permitem que se possa traçar os horizontes da luta feminista no meio rural. É importante que ocorra "a combinação de políticas de promoção de direitos com a força e a organização política, econômica e social das organizações e movimentos de mulheres" capazes de "superar as desigualdades entre homens e mulheres historicamente construídas no meio rural e, também, na reforma agrária"(BUTTO; HORA, 2008, p. 35). A luta pela terra e reforma agrária, portanto, estiveram presentes nas lutas das mulheres, fomentando a organização e mobilização dessas em busca de sua cidadania (MELO; SABBATO, 2008).

Para Melo e Sabbato (2008, p.42), "incorporar a perspectiva de gênero na luta pelo direito à terra implica combinar as definições de rural/urbano e a definição do significado de gênero." Nesse sentido, ao trabalhar a questão de gênero, contextualiza-se "[...] a construção histórica e social do feminino e do masculino para as relações sociais entre os sexos, vividas na sociedade com forte assimetria" (MELO; SABBATO, 2008, p. 42).

\section{As lutas pela reforma agrária e a PARTicipação COletiva das} MULHERES

Para as mulheres entrevistadas, o papel delas na luta pela terra é tão importante quanto o que é desempenhado pelos homens, para elas, todos possuem importantes atuações sejam homens, mulheres ou crianças. De acordo com Ciliana,

No nosso acampamento foi interessante, porque até muitos cadastros inclusive estão no nome das mulheres e foram as mulheres que permaneceram o tempo todo no acampamento, também pela dificuldade de conseguir renda externa. No meu grupo, por exemplo, nós estávamos em 50\% mulheres e 50\% homens. Porque justamente muitas mulheres ficaram no acampamento para os homens irem trabalhar fora para garantir a renda. As mulheres possuem um representação bem significativa (Entrevista realizada em maio, 2019).

As mulheres estão presentes em todos os contextos da sociedade, assim como nas lutas do MST e possuem papéis fundamentais no processo de construção 
dos assentamentos rurais, dada a função de educadoras, de encarregadas pela socialização das/os filhas/os e "responsáveis pelas tarefas de reprodução e, como trabalhadoras rurais, por atividades produtivas na roça ou na casa” (PAVAN, 2000 , p. 30). Mesmo as mulheres, em sua maioria, avaliando que a sua participação é de extrema importância, ainda existem inúmeros desafios para que existam espaços nos quais elas possam participar e se organizar para a luta. Sabendo da participação ativa das mulheres nos contextos de reforma agrária e na luta pela terra, passa-se a questionar quantas delas de fato apropriam-se das terras após essas serem conquistadas. Conforme Paulilo, o acesso à terra e aos direitos das mulheres camponesas é extremamente restrito e mesmo tendo se alterado no contexto do final do século XX e início do XXI, ainda é possível observar a predominância dos filhos homens e o reconhecimento do trabalho masculino (seja pai ou esposo) como provedor da renda familiar, sendo a mulher e as/os filhas/os apenas ajudantes e dependentes do chefe da família (PAULILO, 2016). Vale ressaltar que nos contextos de reforma agrária,

Ao se estruturar o assentamento, entretanto, esse protagonismo feminino, desempenhado em condições equivalentes em relação aos homens na ocupação e no acampamento, se expressa numa aparente resignação diante da condição de subalternidade, imposta social e culturalmente às mulheres. As práticas de enfrentamento, de solidariedade e de resistência desenvolvidas no acampamento e que eram ressaltadas como positivas pelos militantes e dirigentes do MST e pela sociedade de uma maneira geral, são esquecidas pelas próprias mulheres já que se constituem em "ações miúdas" que não aparecem ou contam pouco na luta política (PAVAN, 2000, p. 30).

O contexto do MST pode ser descrito como um espaço no qual as mulheres vêm ampliando as suas lutas e conquistas e o reconhecimento pelo seu trabalho como provedoras da renda familiar e da qualidade da alimentação, mas que ainda demandam maior visibilidade e reconhecimento (PAULILO, 2016). Franciane entende que a participação das mulheres está no "todo", “[...] no conjunto da construção, no debate, na discussão, eu acho que a mulher não pode vir para o lote para ficar naquele quadradinho da casa, ou ficar com um quadradinho para plantar suas coisas, tem que estar na construção do diálogo como um todo" (Entrevista realizada em agosto, 2019).

Nas políticas públicas relacionadas à reforma agrária, esteve presente uma lógica em que se supunha que as famílias estariam representadas pelo homem, como o chefe e provedor da família. Dessa maneira, quando os homens fossem beneficiados, 
as famílias também estariam sendo beneficiadas. No entanto, em muitos países, as mulheres casadas ainda não obtiveram o direito civil total ou o de administrar os próprios bens, predominando a exclusão de gênero (DEERE; LEON, 2002).

Em contextos de reivindicações, os quais Deere e Leon (2002) descrevem como os tijolos de construção de uma mudança progressista, há a necessidade de discutir os caminhos e as lutas para os direitos de gênero e de acesso à terra, nos níveis internacionais, nacionais e locais. O ponto de partida para essas conquistas é a formação e transformação rural, considerando as mulheres e o desenvolvimento, delineando os importantes papéis desempenhados por elas nas lutas pelas políticas públicas, pelos direitos e pela terra. No debate da reforma agrária, o que ainda demanda discussões é a relação de gênero nesses contextos, principalmente pela invisibilidade do trabalho feminino no meio rural e no acesso à terra (MEDEIROS, 1989).

Nos últimos anos, os assentamentos colocaram em debate os arranjos produtivos tradicionais, os quais seguiram por muito tempo os modelos herdados e seguiam hierarquizando as atividades no meio rural. Para Medeiros (1989), é interessante pensar o que significaram as mudanças nas relações de gênero produzidas por experiências como a dos coletivos implantados pelo MST no final dos anos de 1980. Dessa maneira, passou-se a repensar práticas naturalizadas com relação à divisão sexual do trabalho, à organização familiar e às relações de poder; no entanto, não se transformou a dominação masculina nas relações cotidianas (MEDEIROS, 1989). Para Pavan (2000),

Mesmo dentro do MST, existem, ainda, muitos obstáculos a serem superados pelas mulheres, relacionados à capacitação política, ao baixo grau de escolaridade, ao espaço ainda reduzido dentro da organização, à capacidade de lidar com as contradições geradas pelas relações de afetividade que, no campo, se misturam às de trabalho, uma vez que, na maioria das vezes, os papéis de marido, patrão, chefe ou coordenador se confundem. (PAVAN, 2000, p. 42).

\section{Vale refletir que os movimentos sociais possuem um}

[...] papel importante no alavancamento de políticas públicas, como a luta pela terra na efetivação da política de assentamentos, o movimento sindical na conquista de direitos como a previdência social rural e um crédito agrícola voltado especificamente para a agricultura familiar, entre outros exemplos. Nesse sentido, podemos afirmar que os movimentos sociais rurais, através de suas lutas, influenciaram na redução das desigualdades entre zona rural e urbana, tendo efeitos positivos sobre a vida do conjunto 
dos trabalhadores e trabalhadoras rurais, tendo favorecido o acesso das mulheres a direitos e a políticas públicas (HEREDIA, CINTRÃO, 2006, p. 6).

As mulheres camponesas fazem parte de diversos movimentos sociais e lutam por mudanças e/ou transformações de suas posições hierarquicamente inferiores na estrutura social. Os movimentos sociais são importantes organizações que auxiliam e atuam na busca pelos direitos e pela transformação das desigualdades sociais em toda sociedade, como exclusão, discriminação, preconceitos, invisibilização e falta de reconhecimento. Eles tratam dos direitos das mulheres camponesas, do acesso à terra e do reconhecimento e visibilidade delas enquanto trabalhadoras rurais ou agricultoras, as quais possuem e desempenham papéis fundamentais na luta, construção e manutenção das propriedades rurais.

Para Ciliana, essa possibilidade de participação das mulheres é muito positiva, porém deveria ser mais ampla, pois "quando as mulheres estavam mais unidas em determinados espaços do acampamento, a gente via que elas conseguiam estudar, discutir as questões de gênero e estar articuladas para fazerem trabalhos, atividades [...]". (Entrevista realizada em maio, 2019). Ela pontua a importância da organização das mulheres, pois “a participação é frágil ainda, [...] a gente não consegue mais ver como elas estão se reunindo, a gente não consegue mais ver como elas estão articuladas, mas eu acho que assim, de 1000 mulheres, eu não sei se tem 40 ou 50 mulheres no coletivo de gênero" (Entrevista realizada em maio, 2019). O coletivo de gênero, ao qual se refere Ciliana, foi organizado pelas mulheres do acampamento com o intuito de discutir as suas demandas, possibilitando a inserção e a participação delas nas lideranças e cargos do acampamento, como também potencializar os seus papéis enquanto mulheres camponesas.

Ana Ribas relata que:

Eu acho que ainda nós não acordamos, tem uma minoria que está lutando e é nesse papel que a gente ainda não conseguiu romper o machismo, que está muito forte nas mulheres ainda, mesmo com essa demanda de liberdade que nós temos, muitas mulheres ainda, a maioria das companheiras estão presas [às relações patriarcais], elas não tem liberdade. Essa relação machista existe aqui no acampamento e é bem forte" (Entrevista realizada em maio, 2019).

As mulheres entrevistas afirmam que sempre realizaram um conjunto de atividades no acampamento, desde o seu início, porém, atualmente poucas ocupam cargos de liderança. Para Ciliana, a pouca participação das mulheres é reflexo de um período em que o acampamento teve uma atuação "[...] totalmente 
machista, tanto que nós tínhamos um homem e uma mulher que participava da direção estadual e acabou se afastando, afastando as mulheres justamente por isso, por uma relação muito machista." (Entrevista realizada em maio, 2019). Segundo ela, faz aproximadamente dois anos que as mulheres acabaram se afastando e o acampamento, como um todo, regrediu bastante, pois "as mulheres participavam mas nunca tinham voz ativa, mesmo nas atividades. Foi, por falta de entendimento. Não é porque é culpa deles, é, mas é mais por falta de entendimento da importância da participação das mulheres”. (Entrevista realizada em maio, 2019).

As mulheres descrevem que nos grupos sempre se priorizou que houvesse a participação equitativa de um homem e de uma mulher na liderança, porém nunca se trabalhou o porquê dessa regra de participação das mulheres. Para Ciliana, nunca houve uma discussão política sobre isso para que as pessoas pudessem compreender a importância da atuação feminina, elaconsidera necessário que as mulheres participem, "porque nós temos que discutir políticas para as mulheres, porque nós temos que discutir a inserção das mulheres. Você vê isso em muitas propriedades, a relação é totalmente machista, é o homem que coordena tudo." (Entrevista realizada em maio, 2019). As mulheres que ocupam cargos de liderança estão em grupos distintos, na coordenação da escola e em cargos estaduais do MST.

Para as mulheres que não participam, entendem que é uma escolha delas não participar nesse momento; em alguns casos, algumas já haviam ocupado cargos anteriormente. Marisa afirma que as mulheres estão,

[...] inseridas na coordenação, na direção do acampamento, lá na agricultura trabalhando, nas reuniões dos grupos. As mulheres guardam a semente para fazer a troca com as vizinhas, então, as mulheres são muito ativas. De uma forma ou de outra, quando você vai lá na unidade de produção, você vê muita mulher trabalhando de igual para igual com seus companheiros (Entrevista realizada em maio, 2019)

Conforme Ciliana:

[...] a gente percebe, os homens se julgam melhores que as mulheres. Não sei se é pelo fato de eu ser sozinha, não ter marido, que me faz ser mais fraca perante a sociedade, geralmente os homens machistas, eles perseguem... Eu já passei muito por isso e ainda hoje eu passo, de receber calunias por ser uma mulher sozinha, humilhações em público... Por que ela é uma mulher sozinha, não tem direito de estar aqui, é assim que muitos homens pensam, esse machismo, muitas vezes está ligado ao interesse de tirar tua terra e de explorar seu trabalho. (Entrevista realizada em agosto, 2019). 
Para Juliana, os papéis desempenhados pelas mulheres são fundamentais na reforma agrária,

Quando você pergunta isso, eu lembro de várias mulheres que contribuíram nos processos, então... eu acho que sim, a gente tem muito um olhar de reconhecer, de visibilizar o trabalho das mulheres. Eu acho que eu olho muito para esse ponto de vista. Eu diria que $50 \%$ da luta foi construído pelas mulheres. Mesmo que as tarefas sejam diferentes, elas estando em todas as tarefas eu acho que nunca teve uma tarefa, que foi apenas conduzida por homens (Entrevista realizada em maio, 2019).

Na luta e busca pelos direitos das mulheres, através da obtenção de linhas de crédito, do reconhecimento e da valorização do trabalho, a agroecologia surge como uma possibilidade de empoderamento delas. Nessa prática as mulheres participam em todas as etapas, desde o planejamento até a comercialização e venda dos produtos, o que será abordado em seguida, apresentando as lutas dos movimentos sociais e da agroecologia, considerando as mulheres camponesas.

\section{A AgroECOLOGIA COMO INSTRUMENTO DE EMPODERAMENTO DAS} MULHERES NO MST

A agroecologia representa uma ruptura com o paradigma convencional da produção agrícola centrada nos homens. Nela ocorre a valorização do conhecimento local e das mulheres, facilitando a introdução dos temas do feminismo no âmbito rural. Ela vem, portanto, ampliando o olhar ambiental e político do feminismo, em que "temas como as mudanças climáticas e os transgênicos, comuns na agroecologia, passaram a compor os debates feministas" (FERREIRA; MATTOS, 2017 , p. 41). A agroecologia se tornou uma perspectiva de vida que tem se contraposto ao sistema da agricultura convencional que se intensificou no período pós-guerra, em que os produtos químicos de guerra foram transformados em insumos agrícolas e, assim, foi instituída a chamada Revolução Verde, instaurando o modelo da fábrica para a agricultura e para as florestas, a partir do investimento e do apoio técnico e financeiro de instituições internacionais e dos Estados nesses processos. As grandes empresas multinacionais passaram a controlar a produção e comercialização de sementes (híbridas e geneticamente modificadas) e de insumos (fertilizantes químicos, agrotóxicos e máquinas) (SHIVA, 2003).

A agroecologia oferece às mulheres camponesas subsídios para uma maior visibilidade e reconhecimento do seu trabalho e participação na produção para o autoconsumo da família, qualidade dos alimentos, vida no campo e, também, como um importante fator econômico para as famílias. Nesse contexto apresentam-se 
diversas vertentes que abordam a relação entre a agroecologia e as mulheres. $\mathrm{O}$ ecofeminismo apresenta-se como uma dessas vertentes que traz a relação próxima da mulher com a natureza e em especial ao que se relaciona com a maternidade, $o$ cuidado e a reprodução, na perspectiva de reconciliar as mulheres com a natureza. Conforme Franciane,

[...] são as mulheres que descobriram a agricultura, são elas que zelam pelo produzir o alimento saudável para a família comer, optando pela diversificação, sempre pensando no bem da família. Quando sobra o excedente, eu comercializo e faço bastante trocas com as vizinhas, isso desde sempre. Então acredito que na agroecologia as mulheres conseguem ter mais economia, conseguem organizar melhor a produção, a renda principalmente, o produto de qualidade, agregar valor ao produto. Hoje tem um pouco mais de venda, tem as feiras, têm os mercados institucionais, então que tem o preço diferenciado e a gente vê o destaque neste caso das mulheres em começar a produção. (Entrevista realizada em ago. de 2019).

A partir da Conferência Mundial do Meio Ambiente e Desenvolvimento (Eco 92), que ocorreu no Rio de Janeiro, em 1992, passou-se a refletir com mais intensidade sobre os impactos causados ao meio ambiente. Nesse encontro internacional, além de atentar-se às questões da destruição e extinção dos espaços rurais e da diversidade disponíveis no meio, destacou-se a participação das mulheres como sujeitos importantes na preservação ambiental e na produção. A participação delas na prática agroecológica proporcionou-lhes espaços para apresentarem-se como capazes e, ainda, o reconhecimento enquanto agricultoras (SILIPRANDI, 2011; GEORGIN et al., 2015).

Ao abordar a participação das mulheres na prática agroecológica, é possível observar que elas sempre estiveram à frente na busca pela qualidade da alimentação familiar e modificação das relações sociais e ambientais. Torna-se necessário também, atentar-se para o fato de que na agroecologia as mulheres buscam mais reconhecimento enquanto camponesas e produtoras de alimentos e produtos sustentáveis. Uma das interlocutoras de nossa pesquisa, Marisa, chama a atenção para como ocorre essa inserção da mulher na agroecologia, pois se deve tomar cuidado para ela não continuar restrita ao espaço privado:

Se a mulher se fechar na sua unidade de produção, esse modelo continua oprimindo, mas se ela estudar e participar melhora. Se a mulher ficar só na produção e não administrar e é o companheiro quem faz essas coisas, ela acaba só adquirindo mais trabalho e não consegue sua emancipação. Tem que ter muito cuidado com isso, pois as vezes você só 
está adquirindo mais responsabilidades e não tem nenhuma visão do que pode estar acontecendo, de que você está se sobrecarregando, mas não está se libertando (Entrevista realizada em maio, 2019).

Nessa perspectiva, as demais mulheres entrevistadas também chamam a atenção para como se efetiva a agroecologia, que ela deve colocar a mulher em "pé de igualdade" para com os homens, caso contrário, não estará sendo eficaz. Para Elenir,

Para a mulher, o trabalho com a agroecologia dá mais abertura para a mulher. A mulher não precisa de 5 alqueires para trabalhar, se ela tiver 50X50 ela já consegue ter uma boa renda, eu acho que isso que aumenta a autonomia da mulher, ela não precisa se matar trabalhando para ter uma boa renda, a gente não consegue ver isso aqui, mas via isso lá no acampamento e também em outros espaços. Eu acho que a mulher tem mais espaço, só olhar nas feiras, tem muito mais mulher do que homens. (Entrevista realizada em maio, 2019).

Franciane descreve que "[...] a agroecologia dá muita autonomia para as mulheres e também é com ela que essas mulheres conseguem quebrar esse tabu, essa barreira dentro da própria casa, com seus próprios companheiros, com suas/ eus filhas/os" (Entrevista realizada em agosto, 2019).

É possível verificar que os espaços de discussão sobre a participação das mulheres na prática agroecológica vêm se ampliando em congressos, cursos e formações na busca de sistematizar e ampliar a visibilidade e o reconhecimento dos papéis desempenhados por elas. Nesses espaços são discutidas temáticas pertinentes à agroecologia enquanto ciência, prática e movimento para alcançar a soberania alimentar. Problematizando a modernização do campo, o qual visou exclusivamente o aumento da produção, associado à masculinização do meio rural, em que os homens se colocam no papel de chefes de família, logo, são eles que se tornam beneficiários dos programas de incentivo do governo. A agroecologia é vista como um processo de resistência à modernização, a qual é diferenciada para homens e mulheres e na qual elas possuem mais responsabilidades e menos recursos. Os principais objetivos da sistematização de experiências protagonizadas pelas mulheres na agroecologia são:

[...] 1) dar visibilidade às experiências promovidas por mulheres na Agroecologia; 2) elaborar e experimentar uma metodologia participativa de sistematização, aprimorando a capacidade das mulheres de refletir sobre suas próprias experiências; 3 ) refletir sobre o papel das mulheres na construção da Agroecologia e o papel da Agroecologia na vida das 
mulheres; e 4) gerar referências para a formulação de políticas públicas a partir dos aprendizados das experiências sistematizadas (CARDOSO; RODRIGUES, 2009, p. 12).

Através da agroecologia, as mulheres passam a ter um maior reconhecimento das suas atividades e funções, garantindo-lhes visibilidade. A agroecologia, além do que já foi descrito, possui em suas interfaces inúmeras propostas de transformação das relações e formas de organização social. Para Franciane, "hoje o movimento tem mais esse debate da agroecologia, se tem esse debate, consequentemente tem mais oportunidade, então dentro desse debate de gênero, vem esse debate de agroecologia, então as mulheres conseguem ter mais participação (Entrevista realizada em agosto, 2019)"

Nessa mesma perspectiva, na busca pela equidade e diversidade, almeja-se a valorização e visibilidade da contribuição das mulheres no desenvolvimento da sociedade, na busca por mais justiça e igualdade. O feminismo é para todos e questiona a heteronormatividade que produz o modelo hegemônico de relações societárias. Dessa maneira, “[...] o feminismo aqui abordado também está relacionado a uma teoria e a um movimento que se retroalimentam e, de várias formas, põe em relevo a opressão que o gênero masculino exerce sobre o gênero feminino" (FERREIRA; MATTOS, 2017, p. 38). O feminismo e a agroecologia, portanto, propõem lutas e transformações sociais para diversos contextos e perspectivas da sociedade na busca pelos direitos dos seres humanos, como a cidadania, democracia, política, contra a pobreza e no incentivo aos movimentos sociais, os quais estão à frente das reivindicações por esses e outros direitos da sociedade (FERREIRA; MATTOS, 2017). Deste modo,

A perspectiva agroecológica tem demonstrado potencial de abrir espaços para que as mulheres agricultoras enfrentem sua condição de vulnerabilidade e, neste sentido, conquistem mais poderes nas esferas pessoal, produtiva, familiar e política. Entretanto, o trabalho com a agroecologia, por si só, não é suficiente para que a desvalorização e a invisibilidade das mulheres sejam suficientemente problematizadas. Neste sentido, o diálogo entre as perspectivas agroecológica e feminista é um importante caminho para o enfrentamento político sobre alguns dos dilemas vivenciados pelas mulheres no meio rural (FERREIRA; MATTOS, 2017, p. 39).

Para Siliprandi (2011), as mulheres devem ser reconhecidas como sujeitos políticos pela luta ecológica, que está associada ao feminismo e que se constitui enquanto um marco interpretativo que permite dar visibilidade aos 
relacionamentos opressivos entre homens e mulheres. Assim, é importante que se possa compreender as inúmeras formas como se reproduz a opressão com relação às mulheres bem como a naturalização dessas relações cotidianas na sociedade. Percebe-se, desse modo, que "[...] esta nova prática trouxe uma maior responsabilidade a estas mulheres", mesmo que elas não tenham total controle sobre os ganhos econômicos, "elas passaram a se sentir mais livres, ao mesmo ponto em que podem participar das decisões que antes só cabiam aos homens" (GEORGIN et al., 2015, p. 6). Para Brumer (2004, p. 211), em seus estudos, a divisão do trabalho no meio rural ainda é marcada fortemente pela divisão sexual e "permitem concluir que as mulheres (e, de um modo geral, também as crianças e os jovens) ocupam uma posição subordinada e seu trabalho geralmente aparece como 'ajuda', mesmo quando elas trabalham tanto quanto os homens ou executam as mesmas atividades que eles." De forma que,

As mulheres, ainda, responsabilizam-se praticamente sozinhas pelo trabalho, no qual com freqüência são auxiliadas ou substituídas pelas filhas, quando têm outra atividade. Nessa esfera, as mulheres têm autonomia e poder, tomando decisões relativas ao preparo dos alimentos, cuidado da casa e da roupa, orientação e educação dos filhos, assim como ao uso de recursos destinados ao consumo doméstico. Elas também tomam decisões referentes a vendas eventuais de bens por elas produzidos, tais como ovos, queijo, nata, e outros, sendo também as responsáveis pelo uso dos recursos assim obtidos. No entanto, não se deve superestimar a importância de sua autonomia e poder nesse domínio, tendo em vista, por um lado, que as vendas feitas por elas geralmente são eventuais e de pequeno valor e, por outro, que as atividades domésticas são consideradas como secundárias, pelos próprios membros da família, em relação às atividades produtivas. (BRUMER, 2004, p. 211-212).

Deste modo, é comum essa forma de divisão no âmbito do trabalho familiar, no qual prevalece a hierarquia e a divisão marcada pelo sexo dos sujeitos. Consequentemente as mulheres historicamente são responsáveis pelas atividades do espaço doméstico e pelo trabalho na propriedade, principalmente os de cunho privado, enquanto aos homens cabe o trabalho na propriedade e a representação familiar no meio externo, como agricultores e/ou trabalhadores rurais. Para Brumer (2004):

Dois aspectos podem explicar a divisão de trabalho que se estabelece entre homens e mulheres rurais. O primeiro é que a unidade familiar de produção caracteriza-se por reunir os esforços de todos os membros da família, com 
vistas ao benefício de todos, havendo uma necessária aproximação entre unidade de produção e unidade de consumo. O segundo é que vivemos em uma sociedade paternalista, e de certo modo machista, em que se atribui ao homem o papel de responsável pelo provimento da família. Ocorre que as atividades geralmente desenvolvidas pelas mulheres na esfera produtiva dos estabelecimentos agropecuários requerem algumas qualidades que supostamente as mulheres (adultas e jovens) possuem (por natureza ou por aquisição, através do processo de socialização) ou que sua situação de trabalhadoras eventuais propicia (devido à manutenção de suas obrigações na esfera da reprodução) (BRUMER, 2004, p. 212).

As mulheres permanecem, dessa maneira, invisibilizadas nos trabalhos que realizam na propriedade rural. Mesmo que trabalhem de igual para igual ou até mesmo, em muitos casos, mais do que os homens, não são reconhecidas de fato pelo trabalho que realizam e são descritas como ajudantes ou dependentes de seus companheiros e pais. $\mathrm{Na}$ agroecologia, busca-se, então, repensar novas formas de organização familiar, nas quais as mulheres possam ser viabilizadas enquanto trabalhadoras rurais, a agroecologia possibilita visibilidade e reconhecimento para as atividades que elas desenvolvem e produzem. Para Franciane, na agricultura

[...] é difícil pensar isso separado, cada um em um quadradinho, porque é um constante movimento, na verdade é como se fosse uma engrenagem, se tirar um parece que não flui, se você tira as Mulheres do processo não flui o debate, não anda. A questão da agroecologia também, que hoje a gente vê que aderiram à agroecologia por parte das mulheres, não foi por iniciativa, nem por vontade dos homens, os homens aderiam a agroecologia a partir do momento que viram que dava dinheiro, da renda, ai é eu que vou gestionar, é eu que vou cuidar, ai o movimento sempre tenta discutir essa questão de gênero, da igualdade, então não tem como pensar todo esse processo sem as mulheres. Isso não me passa pela cabeça. (Entrevista realizada em agosto, 2019).

Quando se compreende a relação entre o feminismo e a prática agroecológica, evidenciam-se os diversos dilemas vivenciados pelas mulheres no meio rural. Essas perspectivas propõem a extinção de ações que invisibilizam a participação e o trabalho delas, já que a união entre essas amplia a possibilidade de discussão e reflexões no enfrentamento de práticas que se tornaram naturalizadas no cotidiano da sociedade (FERREIRA; MATTOS, 2017).

Dessa maneira, a agroecologia e o feminismo evidenciam saberes e práticas tradicionais, vistos em muitos casos como sinônimo de "atraso" ou "retrocesso", 
considerando as tecnologias disponíveis atualmente em nossa sociedade. Mas, “ao valorizar o conhecimento local, a perspectiva agroecológica revela a importância das mulheres na construção de sistemas agroflorestais, quintais, hortas, manejo da criação de animais, entre outros sistemas produtivos." (FERREIRA; MATTOS, 2017, p. 41). A introdução do "feminismo na construção do campo agroecológico contribui na ampliação do enfoque para além das questões tecnológicas, produtivas e ambientais. As questões sociais ganham evidência, incluindo a busca da justiça e equidade nas relações de gênero" (FERREIRA; MATTOS, 2017, p. 41). Havendo um consenso de que essas relações são desiguais e injustas, elas devem ser repensadas e construídas socialmente junto com a comunidade. $\mathrm{O}$ feminismo e a agroecologia trabalham juntos para uma nova construção social, possibilitando a retirada de inúmeras mulheres da situação de opressão, visando, garantir uma agricultura sem agrotóxicos e adubos químicos, fomentando a participação em atividades coletivas. Uma das primeiras interfaces entre ecologismo e feminismo foi a discussão sobre o aumento populacional e os direitos reprodutivos das mulheres.

O ecologismo e o feminismo uniram-se inicialmente para elaborar estratégias para diminuir as taxas de crescimento da população mundial, discutindo, posteriormente, o direito reprodutivo das mulheres, garantindo-lhes o poder de escolha com relação à procriação, promovendo o exercer livre de sua sexualidade e sem a obrigatoriedade de ter filhos (SILIPRANDI, 2011).

Por muito tempo as mulheres foram marcadas pelo dualismo entre natureza e cultura, reconhecidas como parte da natureza ou como mediadoras entre natureza e cultura, o que as colocou em uma posição de inferioridade com relação aos homens. Essa posição lhes foi atribuída por conta da sua fisiologia (seu corpo), de seu papel social ligado à maternidade (SILIPRANDI, 2011). Com a aproximação entre o feminismo e a agroecologia,

[...] passou-se a compreender a importância histórica das mulheres na agroecologia, e o quanto elas ainda têm a contribuir na construção desse conhecimento. É fundamental que esse conhecimento venha à tona como construção específica das mulheres. Esta valorização é fundamental para garantir que isso não lhes seja expropriado pelos homens em sistemas economicamente patriarcais (FERREIRA; MATTOS, 2017, p. 42).

A história das mulheres com a agroecologia é caracterizada pela preocupação com os problemas ambientais, delimitando o "ecofeminismo", o qual vem se fortalecendo a partir dos anos 1990, buscando o reconhecimento, reinterpretação e reorganização das relações da humanidade com o meio natural, reivindicando que 
as ações humanas não ocorram a partir de uma perspectiva sexista, mas, sim, de respeito e valorização a todos os seres existentes no meio (SILIPRANDI, 2011):

As mulheres sempre assumiram um papel de destaque na promoção da Agroecologia, seja nas áreas de produção, beneficiamento e comercialização de alimentos ecológicos, seja na geração e disseminação de conhecimentos. Com seu olhar problematizador, fazem uma leitura diferenciada da agricultura e propõem alternativas produtivas e econômicas frequentemente motivadas por questões ligadas à reprodução da vida (AGUIAR, SILIPRANDI, PACHECO, 2009, p. 46).

Na prática agroecológica observa-se a presença ativa das mulheres, diferentemente da agricultura convencional, na qual predominam métodos e abordagens de trabalho em que o homem é o chefe da família e é ele que toma grande parte das decisões pelo círculo familiar. Na agroecologia, observam-se alterações na organização familiar e nos modos de trabalho, diferentes dos presentes na agricultura convencional, no qual se designa que as mulheres desempenham os trabalhos mais "leves" e os homens os trabalhos "pesados", porém essa classificação é determinada pelo sexo de quem realiza as atividades e não porque algumas delas exijam mais forças físicas e outras habilidades (PAULILO, 2016).

Em torno desse debate, é possível afirmar que "a produção agroecológica para as mulheres camponesas vai além de apenas a produção de alimentos sem agrotóxicos, adubos químicos ou a utilização de sementes geneticamente modificadas." (BONI, 2017, p. 22), pois para elas há uma relação mais próxima com o meio, ao respeitarem não apenas a natureza, mas também suas próprias famílias e os consumidores para os quais comercializam os produtos. Para Franciane,

As mulheres possuem papéis fundamentais no processo histórico da humanidade, dentro do processo da agroecologia e se não fosse as mulheres acredito que muita coisa na agricultura não teria avançado e, principalmente na agroecologia e na alimentação saudável, porque hoje quem que são as pessoas que se preocupam com as famílias, com o bem estar, com a alimentação são as mulheres. Dificilmente se você conversa com um homem eles estão preocupados com o alimento para o consumo, eles podem até pensar em plantar um feijão, mas esse feijão é para a venda, para a comercialização, até planta um pouco para o consumo, mas o foco é a venda, a produção. Eu acho que as mulheres possuem seu papel fundamental e caso elas não existissem, o processo para na verdade, sem elas não existe outra possibilidade. (Entrevista realizada em agosto, 2019). 
Ao produzirem alimentos de qualidade, diversificados e de forma ecológica, passam a ter acesso ao ganho econômico e a qualidade de vida, o que reforça, cada vez mais, a proliferação dessa prática (BONI, 2017). Por meio da agroecologia, torna-se "[...] inegável a sua ascensão como protagonistas de uma nova forma de fazer, organizar e viver a agricultura familiar", através de "rearranjos familiares, autonomia econômica, e social" (GEORGIN et al., 2015, p. 8).

Para Boni $(2015$, p. 22) "a produção diversificada para o autossustento, o cuidado com a horta, o pomar, as plantas medicinais, o jardim, tudo isso faz parte da identidade da mulher camponesa". Ainda, de acordo com a autora, é através da participação política, em sindicatos e associações, que as mulheres passaram a adquirir mais direitos, acesso às políticas públicas e à visibilidade social. Para reverter a situação de invisibilidade seria necessário "[...] oferecer-lhes apoio organizativo e possibilitar que as mulheres tivessem acesso a recursos produtivos (terra, crédito, formação técnica) para que pudessem desenvolver suas capacidades" (SILIPRANDI, 2011, p. 103).

Ao refletir sobre as preposições postas sobre a agroecologia e o que esta propõe como um modelo de sociedade e não apenas como uma nova forma de desenvolver a agricultura - como ainda prevalece em muitos espaços e é descrito por muitas pessoas - e ao abordar de fato o que é agroecologia, como visto anteriormente, compreende-se que essa, abrange toda a organização social e assim, ao se compreender seus objetivos e analisar as situações postas, entende-se que a agroecologia ainda possui inúmeros desafios para com a sociedade.

Como descrito ao longo deste estudo, ainda existem muitos desafios com relação ao modelo social estabelecido atualmente, mas muito se vem avançando; no entanto, as mulheres ainda vivenciam inúmeras formas de opressão na sociedade patriarcal em que vivemos. Desse modo, não apenas nesses aspectos, mas em diversos contextos sociais, a agroecologia deve intensificar sua compreensão e efetivação, pois caso não haja harmonia, não está se efetivando a agroecologia, e sim apenas uma agricultura sustentável, o que não se define como o seu objetivo.

\section{CONSIDERAÇões FINAIS}

Ao longo deste estudo, evidenciou-se que o patriarcado ainda predomina em todas as relações na sociedade. As mulheres interlocutoras da pesquisa destacam que já ocorreram muitos avanços com relação ao machismo e às relações de poder, no entanto, ainda vivênciam situações cotidianas que reforçam e invisibilizam as mulheres e as atividades por elas desempenhadas.

Muito já se avançou, contudo, ainda há inúmeros enfrentamentos vivenciados pelas mulheres no seu cotidiano. As mulheres entrevistadas, do acampamento Herdeiros da Terra de $1^{\circ}$ de maio, denotam as transformações que vivenciam 
através da agroecologia, não apenas na questão alimentar ou trabalho, mas como um modo de vida e de organização social. Para elas, a agroecologia vai muito além de um modelo de agricultura, mas se trata, sim, da possibilidade de enfrentamento das dificuldades por elas vivenciadas em seu cotidiano e todas relatam que a agroecologia transformou suas vidas, desde os seus hábitos alimentares até o modo de relacionar-se com o meio ambiente e as percepções sobre o que é agricultura. Nota-se, ao longo deste estudo, que o número de famílias que trabalham com agroecologia é baixo quando comparado ao número total de famílias do acampamento, porém eles fazem parte de uma importante parcela de resistência a um modelo de agricultura e sociedade ainda hegemônicas.

\section{REFERÊNCIAS}

AGUIAR, Maria Virgínia; SILIPRANDI, Emma; PACHECO, Maria Emília. Mulheres no Congresso Brasileiro de Agroecologia. Mulheres construindo a Agroecologia. Rev. Agriculturas: experiências em agroecologia. Leisa Brasil, v. 6 n. 4, dez. 2009. Disponível em: <http://aspta.org.br/wp-content/uploads/2011/05/Agriculturas_v6n4.pdf>. Acesso em: jan. 2019.

BEAUVOIR, Simone de. O segundo sexo: a experiência vivida. 2. ed. São Paulo: 1967.

BONI, Valdete. Organização produtiva de mulheres e promoção de autonomia por meio do estimulo à prática agroecológica. In: Org.: Valdete Boni; Lucélia Peron; Siomara Aparecida Marques; Naira Estela Roesler Mohr e Tania Mara De Bastiani. Mulheres camponesas e agroecologia. CRV: Curitiba, Brasil. 2017.

BRUMER, Anita; PAULILO, Maria Ignez. As agricultoras no sul do Brasil. Estudos Feministas, Florianópolis, v. 12, n. 1, p. 171-174, 2004.

BRUMER, Anita; ANJOS, Gabriele dos. Gênero e reprodução social na agricultura familiar. Revista NERA, Presidente Prudente, ano 11, n. 12, p. 6-17, 2008.

BRUMER, Anita. Gênero e agricultura: a situação da mulher na agricultura do Rio Grande do Sul. Rev. Estud. Fem., Florianópolis, v. 12, n. 1, p. 205-227, 2004.

BUTTO, Andrea; HORA, Karla Emmanuela R. Mulheres e reforma agrária no Brasil. In: LOPES, Adriana L.; ZARZAR, Andrea Butto (Org.). Mulheres na refor- 
ma agrária: a experiência recente no Brasil. Brasília: MDA, 2008.

CARDOSO, Elisabeth Maria; RODRIGUES, Vanessa Schottz. Mulheres construindo a Agroecologia no Brasil. Rev. Agriculturas: experiências em agroecologia. Leisa Brasil, v. 6, n. 4, dez. 2009. Disponível em: <http://aspta.org.br/wp-content/ uploads/2011/05/Agriculturas_v6n4.pdf>. Acesso em: jan. 2019.

CEZIMBRA, Elemar do Nascimento; PASTÓRIO, Inês Teresinha; XAVIER, Leonardo Pereira. Jovens, lutas por terra e permanência no campo. Curitiba, v. 5, n. 1, p. 27-45, jan. 2019. Disponível em: <http://www.brjd.com.br/index.php/BRJD/ article/viewFile/538/663>. Acesso em: fev. 2019.

CHAYANOV, Alexander. La organizacion e la unidad econômica campesina. Buenos Aires: Edições Nueva Visión, 1974.

DEERE, Carmem; LEON, Madalena. O empoderamento da mulher. Porto Alegre:UFRGS, 2002.

FERREIRA, Ana Paula Lopes; MATTOS, Luis Cláudio. Convergências e divergências entre feminismo e agroecologia. Cienc. Cult., São Paulo, v. 69, n. 2, p. 38-43, 2017. Disponível em: <http://cienciaecultura.bvs.br/scielo.php?script=sci_arttext\&pid=S0009-67252017000200013\&lng=en\&nrm=iso > . Acesso em: jan. 2019.

GEORGIN, Jordana; WIZNIEWSKY, José Geraldo; OLIVEIRA, Gislayne Alves; ROSA, Ana Lúcia Denardin da. A participação feminina na agricultura agroecológica: um estudo do caso na região norte do Rio Grande do Sul. Revista Monografias Ambientais (REMOA-UFSM), Santa Maria, v. 14, n. 3, 2015.

HEREDIA, Beatriz Maria Alásia de; CINTRÃO, Rosângela Pezza. Gênero e acesso a políticas públicas no meio rural brasileiro. Revista NERA, Presidente Prudente, ano 9, n. 8, jan./jun. 2006. Disponível em <http://revista.fct.unesp.br/index.php/ nera/article/view/1443/1420>. Acesso em: jan. 2019.

MEDEIROS, Leonilde Servolo de. História dos movimentos sociais no campo. Rio de Janeiro: FASE, 1989.

MELO, Hildete Pereira de; SABBATO, Alberto Di. O Censo da Reforma Agrária de 1996 e 1997 em uma Perspectiva de Gênero. In: LOPES, Adriana L.; ZARZAR, 
Andrea Butto (Org.). Mulheres na reforma agrária a experiência recente no Brasil. Brasília: MDA, 2008.

PAULILO. Maria Ignes S. Mulheres rurais: quatro décadas de diálogo. Florianópolis: Editora da UFSC, 2016.

PAVAN, Dulcinéia. O caminho feminino para a reforma agrária. Revista NERA, Presidente Prudente, n. 3, 2000. Disponível em: <http://revista.fct.unesp.br/index. php/nera/article/view/1482/1458>. Acesso em: jan. 2019.

SAFFIOTI, Heleieth. Gênero, patriarcado, violência. Expressão popular: São Paulo, 2015.

SHIVA, Vandana. Monoculturas da mente: perspectivas da biodiversidade e da biotecnologia. São Paulo: Gaia, 2003.

SILIPRANDI, Emma. Mulheres agricultoras no Brasil: sujeitos políticos na luta por soberania e segurança alimentar. Pensamiento Iberoamericano, n. 9, p. 169$183,2011$. 